\title{
Rainfall in growing season determines the size of an annual-dominated soil seed bank in a desert ecosystem
}

\author{
Ya-Fei Shi ${ }^{1}$, Zengru Wang ${ }^{2}$, Bing-Xin $\mathrm{Xu}^{1}$, Jian-Qiang $\mathrm{Huo}^{1}$, Rui $\mathrm{Hu}^{1}$, Yang Zhao ${ }^{3}$, and \\ Zhi-Shan Zhang ${ }^{3}$ \\ ${ }^{1}$ Northwest Institute of Eco-Environment and Resources, Chinese Academy of Sciences \\ ${ }^{2}$ Northwest Institute of Eco-Environment and Resources \\ ${ }^{3}$ Chinese Acad Sci
}

December 11, 2020

\begin{abstract}
Soil seed banks may offer great potential for restoring and maintaining desert ecosystems that have been degraded by climate change and anthropogenic disturbance. However, few studies have explored the annual dynamics in the composition and relative abundance of these soil seed banks. We conducted a long-term observational study to assess the effects of environmental factors (meteorology and microtopography) and aboveground vegetation on the soil seed bank of the Tengger Desert, China. The desert seed bank was dominated by annual herbs. We found that more rainfall in the growing season increased the number of seeds in the soil seed bank, and that quadrats at relatively higher elevations had fewer seeds. The species composition had more similarity in the seed bank than in the aboveground vegetation, though the seed bank and aboveground vegetation did change synchronously due to the rapid propagation of annuals. Together, our findings suggest that the combined effects of environmental factors and plant life forms determine the species composition and size of soil seed banks in deserts. Thus, if degraded desert ecosystems are left to regenerate naturally, the lack of shrub and perennial herb seeds could crucially limit their restoration. Human intervention and management may have to be applied to enhance the seed abundance of longer-lived lifeforms in degraded deserts.
\end{abstract}

\section{Title Page}

Title: Rainfall in growing season determines the size of an annual-dominated soil seed bank in a desert ecosystem

Running Head: the dynamics of soil seed bank

Authors: Ya-Fei $\mathrm{Shi}^{1,2}$, Zeng-Ru Wang ${ }^{1}$, Bing-Xin $\mathrm{Xu}^{1,2}$, Jian-Qiang Huo ${ }^{1,2}$, Rui $\mathrm{Hu}^{1}$, Yang Zhao ${ }^{1 *}$, ZhiShan Zhang ${ }^{1^{*}}$

${ }^{1}$ Shapotou Desert Research and Experiment Station, Northwest Institute of Eco-Environment and Resources, Chinese Academy of Sciences, Lanzhou 730000, Gansu, PR China

${ }^{2}$ University of Chinese Academy of Sciences, Beijing 100049, PR China

\section{Correspondence}

${ }^{1}$ Y. Zhao, Northwest Institute of Eco-Environment and Resources, Chinese Academy of Sciences, PR China. E-mail: zhaoyang66@126.com

${ }^{2}$ Z.S. Zhang, Northwest Institute of Eco-Environment and Resources, Chinese Academy of Sciences, PR China. 
E-mail: zszhang@lzb.ac.cn

Author contributions: Z. S. Zhang and Y. Zhao designed research, Y.F. Shi analyzed the data and wrote the paper; Z.R. Wang, B.X. Xu, J.Q. Huo, and R. Hu acquired and analyzed data.

\begin{abstract}
Soil seed banks may offer great potential for restoring and maintaining desert ecosystems that have been degraded by climate change and anthropogenic disturbance. However, few studies have explored the annual dynamics in the composition and relative abundance of these soil seed banks. We conducted a long-term observational study to assess the effects of environmental factors (meteorology and microtopography) and aboveground vegetation on the soil seed bank of the Tengger Desert, China. The desert seed bank was dominated by annual herbs. We found that more rainfall in the growing season increased the number of seeds in the soil seed bank, and that quadrats at relatively higher elevations had fewer seeds. The species composition had more similarity in the seed bank than in the aboveground vegetation, though the seed bank and aboveground vegetation did change synchronously due to the rapid propagation of annuals. Together, our findings suggest that the combined effects of environmental factors and plant life forms determine the species composition and size of soil seed banks in deserts. Thus, if degraded desert ecosystems are left to regenerate naturally, the lack of shrub and perennial herb seeds could crucially limit their restoration. Human intervention and management may have to be applied to enhance the seed abundance of longer-lived lifeforms in degraded deserts.
\end{abstract}

\title{
Keywords
}

Desert ecosystem, seed bank dynamics, rainfall, plant types, vegetation regeneration

\section{Introduction}

Desert ecosystems, limited by water and nutrients, are well known for their scarce vegetation as well as for how easily they are affected by anthropogenic disturbance and climate change, including warming, periodic droughts, and altered precipitation regimes (Bai et al., 2020; Reynolds et al., 2007; Sommer et al., 2011). Because of high seed dormancy, the soil seed bank may have great potential to restore and maintain degraded desert ecosystems (Jacquemyn, Van Mechelen, Brys, \& Honnay, 2011; X. R. Li, Jia, Long, \& Zerbe, 2005). The seed bank maximizes the diversity of native species, provides a source for regeneration of vegetation after disturbance, and also increases the resistance of plant communities to invasive alien species (Arruda, Buisson, Poschlod, \& Silveira, 2018; J. P. Bakker, Poschlod, Strykstra, Bekker, \& Thompson, 1996; M. J. Ma et al., 2019). Understanding the composition and dynamics of soil seed banks is therefore a pressing issue (Huang, Footitt, Tang, \& Finch-Savage, 2018; Montiel \& Montaña, 2003; Nano, Bowland, \& Pavey, 2013). However, compared with aboveground vegetation, our understanding of soil seed banks in desert areas is lacking (Snyman, 2013).

Two main environmental factors influence the species composition and abundance of seed banks in desert soils. First, meteorological factors, such as rainfall in the growing season, can determine the growth and reproduction of aboveground vegetation, and thus affect seed yields (Royo \& Ristau, 2013). Furthermore, rainfall events also cause soil heterogeneity, which could further influence seeds upon entering the soil (Hu, Zhang, Chen, Chang, \& Hou, 2019). Prevalent wind direction and speed contribute to variation in seed dispersal because most desert taxa are anemochorous (Ozinga, Bekker, Schaminee, \& Van Groenendael, 2004; Tackenberg \& Stöcklin, 2008). Second, microtopographic conditions, such as elevation and slope of the quadrat, not only determine seed yields indirectly, through driving the distribution of the aboveground vegetation (Gomaa, 2014), but also cause soil microtopographic and photothermal differences which might have further impact on seed input and germination (Boudell, Link, \& Johansen, 2002; Qian, Liu, Hatier, \& Liu, 2016). However, the relative effects of these environmental factors on the species composition and size of desert soil seed banks is unknown.

Beyond the environmental conditions, the aboveground vegetation also determines the composition and dynamics of soil seed banks (Jan P. Bakker \& Berendse, 1999; Brändel \& Schütz, 2005). Due to the extreme 
environmental conditions in deserts, the different plant lifeforms and their variety of reproductive strategies may play a key role in the soil seed bank. For example, some shrubs and perennial herbs (from now on referred to as "perennials") that depend on a combination of vegetative and seed reproduction methods tend to occur less frequently and thus have lower relative abundance in the seed bank (F. Y. Ma, Li, Long, $\&$ Zhang, 2002). However, patches of soil under shrubs could accumulate larger seed banks because many wind-dispersed seeds may be trapped by the clumped vegetation (Aguiar \& Sala, 1997). More importantly, differences in soil microhabitats caused by shrubs may affect seed germination and persistence (Sternberg \& Yu, 2004). Alternatively, many annual herbs (from now on referred to as "annuals") opportunistically produce a large number of seeds in their short and erratic growing season (J. P. Bakker et al., 1996). Because of this high seed production, annuals tend to contribute more to soil seed banks than other lifeforms.

The species diversity and size of the seed bank is the result of the balance between seed input and seed output in the soil. Seed input depends directly on the local aboveground vegetation that disperses seed locally, as well as on less frequent long-distance dispersal events (Jaganathan, Dalrymple, \& Liu, 2015). Local environmental conditions drive the composition of the vegetation, as well as the presence of herbivores that may consume seeds before they arrive in the seed bank (J. P. Bakker et al., 1996). Conversely, seed output is driven by germination, consumption by herbivores, and destruction by pathogens (Fenner \& Thompson, 2005). Germination depends in part on the role of dormancy, which varies within and between species (FinchSavage \& Leubner-Metzger, 2006). Temperature and light requirements may drive species to accumulate a persistent seed bank (Kleemann \& Gill, 2013). For example, former studies in arid grassland and alpine meadows showed that changes in the species composition and density of the soil seed bank were smaller than those in the aboveground plant communities (Kalamees, Püssa, Zobel, \& Zobel, 2013; M. J. Ma, Dalling, Ma, \& Zhou, 2017). It seems likely that the species composition and size of soil seed banks fluctuates less than plant communities which thus may suggest great potential in the ability of soil seed banks to reconstruct and restore degraded desert ecosystems.

To test these questions, we conducted a long-term observational study (four years of soil seed bank measurements and eight years of aboveground vegetation measurements) in a typical desert ecosystem to determine how environmental factors and aboveground vegetation affect the composition and size of the soil seed bank. We hypothesized that 1) environmental factors, especially rainfall, directly and indirectly affect the seed bank through their effects on the growth of aboveground vegetation; 2) the seeds of annuals dominate in driving changes in the size of the seed bank because of their unique reproductive strategy; and 3) due to the combined effects of environmental factors and aboveground plants, the species composition of the soil seed bank will have more similarity year to year than the aboveground vegetation community.

\section{Materials and Methods}

\subsection{Study site}

The study site, Hongwei, was located on the southeast edge of the Tengger Desert in northwestern China $\left(37^{\circ} 27^{\prime} \mathrm{N}, 104 \mathrm{deg} 46^{\prime} \mathrm{E}\right.$, elevation: $1570 \mathrm{~m}$ a.s.l.). This area is a transitional zone from sandy desert to steppe (Fig. S1a and b), with an 8-month growing season from March to October (Chen, Zhang, Zhao, Hu, \& Zhang, 2018). The mean annual temperature is about 9.6, ranging from -25.1 in January to 38.1 in July. The mean annual precipitation is about $186 \mathrm{~mm}$, with most occurring from June to September. The annual potential evaporation is as high as $2900 \mathrm{~mm}$. The mean annual wind velocity is $2.9 \mathrm{~m} \mathrm{~s}^{-1}$, and dust events are recorded 122 days per year, on average. The soil type in this area is aeolian sandy soil (FAO/UNESCO 1974), characterized by a covering of biological soil crusts and low soil organic matter and nutrient content (Chen et al., 2018). The predominant plant groups are shrubs, annuals, and perennials (Table S1 and S2).

\subsection{Seed bank sampling and seedling emergence}

At the study site, a $148 \mathrm{~m} \mathrm{x} 4 \mathrm{~m}$ transect across the microtopography was established and divided into 37 quadrats of $4 \mathrm{~m} \mathrm{x} 4 \mathrm{~m}$ (Fig. S1c and d). To examine species composition and abundance in the soil seed bank, we collected soil samples in early March from 2012 to 2015. At that time, the seeds have not yet germinated, but also no new seeds have been produced. Thus, the seed bank can be regarded as representative of the 
previous year after seed production and input. In each quadrat, five cylindrical soil cores $(7 \mathrm{~cm}$ in diameter and $5 \mathrm{~cm}$ in depth) were taken, placed in a quincunx, and mixed into a composite sample (Fig. S1c) $(n=$ 37 composites for each year). After each sampling, the soil core locations were marked, so the next year's sampling could be taken $10 \mathrm{~cm}$ away in same direction. The soil samples were transported to Shapotou Desert Research and Experiment Station (SDRES) of the Chinese Academy of Science, and sieved through a $6 \mathrm{~mm}$ mesh to remove plant fragments, coarse debris, and stones.

The seedling emergence method was used to determine the species composition and abundance of the germinable seed bank (Chang, Jefferies, \& Carleton, 2001; Wolters \& Bakker, 2002). First, thirty-seven plastic pots $(30 \mathrm{~cm}$ in diameter and $30 \mathrm{~cm}$ in depth) with drainage holes in the bottom were filled to $20 \mathrm{~cm}$ depth with sandy soil collected from the moving sand dunes. The soil was oven-dried at $150 \operatorname{deg} \mathrm{C}$ for $4 \mathrm{~h}$ to kill any living seeds. Then, the soil samples were distributed evenly on the sandy surface of each pot to about $1 \mathrm{~cm}$ depth (M. J. Ma et al., 2017). The pots were covered with a light-transmitting plastic net to catch any incoming seeds and were watered every day. The pots were inspected weekly for any emerging seedlings. Once they could be identified, seedlings were removed to keep densities low. Unknown seedlings were transplanted to separate plots and grown until identification was possible. The germination experiment continued for 7 months, and the monitoring ceased when no more seedlings emerged for two consecutive weeks. The soil was then sifted and inspected carefully for any remaining seeds.

\subsection{Measurement of aboveground vegetation and environmental factors}

To measure the aboveground vegetation, surveys were conducted every September from 2009 to 2016. All species encountered in the soil seed bank and in the aboveground vegetation were classified by lifeform (shrubs, perennials, or annuals; Tables S1 and S2). The composition, abundance, and coverage of shrubs were determined for each large quadrat $(4 \mathrm{~m} \mathrm{x} 4 \mathrm{~m})$. The presence, abundance, and coverage of herbs were measured in four $0.5 \mathrm{~m} \mathrm{x} 0.5 \mathrm{~m}$ quadrats (Fig. S1c) placed at one-meter intervals in every large quadrat ( $n=148$ herb quadrats). After collecting this data, aboveground samples of all herb species were taken. Litter was also sampled in each herb quadrat. The herb biomass and litter samples were transported to the laboratory, oven-dried at 65 for $48 \mathrm{~h}$ and weighed to determine biomass.

Nine $3.2 \mathrm{~m}$ neutron access tubes were buried along the transect in 2009. Soil water content (0-3.0 m depth) was measured using a neutron probe (CNC503DR, Beijing Nucleon Instrument Company, Beijing, China) twice monthly during the growing season (March to October) and once monthly during the non-growing season (November to February). A micro-weather station (HOBO U30 weather stations, Onset Computers, Bourne, MA, USA) was established in 2009 about $500 \mathrm{~m}$ from the study site to collect half-hourly data on rainfall, air temperature and humidity, solar radiation, and wind direction and velocity. For the microtopographic factors, the elevation, slope gradient and slope aspect of each $4 \mathrm{~m} \mathrm{x} 4 \mathrm{~m}$ quadrat were calculated in 2009 after measuring the coordinates using a high-precision real-time kinematic instrument (S86, South, Guangzhou, China).

\subsection{Data analysis}

Structural equation models (SEM) were used to explore how the environmental factors (i.e., meteorology during the measured years and microtopography of quadrats) and the aboveground vegetation characteristics affected the species richness and abundance of the seed bank. The aboveground vegetation variables included species richness, abundance for three life forms and total species, respectively. The microtopographic factors were elevation, slope gradient and slope aspect of each quadrat. Of the meteorological factors, rainfall, soil water content and wind velocity were considered in our preliminary model, and each meteorological factor was classified into 10 variables (i.e., growing season (April to October), non-growing season (November to March), spring (March to May), summer (June to August), autumn (September to November), winter (December to February), spring-summer, summer-autumn, autumn-winter, winter-spring). Meanwhile, soil water content was first divided into seven layers (i.e., 0-0.4, 0.4-1.0, 1.0-2.0, 2.0-3.0, 0-1.0, 0-2.0, and 0-3.0 m). Before constructing the model, a correlation analysis was conducted between meteorological variables, aboveground vegetation variables and soil seed bank richness and abundance. The correlation coefficients (absolute value) 
for the meteorological variables were generally larger during the growing season than at other times, and thus the growing season data was selected for use in the model. In addition, the correlation coefficient between the aboveground vegetation and soil seed bank did not differ significantly between different life forms, and thus the species richness and abundance of aboveground vegetation were calculated as the sum of the three life forms, transformed in the same scale.

Because of the difference in the temporal and spatial scales of meteorological factors and microtopographic factors in our study, we constructed one SEM for each. Because local microtopography has a greater influence on the distribution pattern of shrubs in the site, we included shrub coverage as an intermediate variable in the microtopography model. These two models included all possible pathways to quantify the plausible impacts of environmental and vegetative factors on the soil seed bank. A Chi-square test, the index of goodness-of-fit (GFI), comparative fit index (CFI) and the root mean square error of approximation (RMAEA) were used to evaluate the fit of the model. Before analysis, all data was log-transformed to improve normality.

Nonmetric multidimensional scaling analysis (NMDS) was applied to assess the similarity of species composition between the aboveground plant communities and the soil seed bank (Clarke, 1993). For each species in the soil seed bank and aboveground vegetation, we calculated the relative abundance and performed the ordination among all the measured years for the three life forms and total species, respectively. We calculated the similarity matrices using the Bray Curtis coefficient, and it was found that the stress value should be smaller than $20 \%$ to reflect the species abundance data accurately (Kindt \& Coe, 2005). To quantify the differences in species abundance, we measured the ordination distances of the soil seed bank polygon and the aboveground vegetation polygon, as well as the distance between them based on the first two axes of the NMDS results. The mean value, standard error and coefficient of variation (CV) of the ordination distance were all calculated for the seed bank and aboveground vegetation, respectively, and the mean values were compared at a 0.05 significance level using a post-hoc HSD test.

The statistical analysis was conducted using the software $\mathrm{R}$ ( $\mathrm{R}$ version 3.6.0), and the following packages: "vegan" for the NMDS analysis (Oksanen et al. 2019), and "ggplot2" (Wickham 2016) for plotting the histograms and the NMDS figures. The SEM was conducted using AMOS 21.0 (IBM SPSS, USA).

\section{Results}

\subsection{Properties and dynamics of the soil seed bank and aboveground vegetation}

From the 1646 seeds that germinated from the soil samples taken at our study site over four years, we identified 17 species belonging to 8 families (Table S1). Of these, 8 species (47\%) were annuals, $6(35 \%)$ were perennials, and $3(18 \%)$ were shrubs. Total species richness varied from 13 to 17 in any one year. Annuals accounted for most (75\%) of the individual germinated seeds, followed by perennials (15\%), and shrubs (10\%). Artemisia capillaris, an annual, comprised more than half $(66 \%)$ of the individual seeds in the soil seed bank. The mean species richness and seed abundance were relatively higher in 2012 and 2014 (measured in 2013 and 2015, respectively), than in 2011 and 2013 (measured in 2012 and 2014) (Fig. 1a and $1 \mathrm{c})$.

In the eight years of surveys of aboveground vegetation, we identified 24 species in 11 families. Of these, annuals accounted for 12 species (50\%), perennials 8 species (33\%), and shrubs 4 species (17\%) (Table S2). Similar to the seed bank, annuals accounted for most (50\%) of the individuals, followed by perennials (34\%), and shrubs (16\%). Species richness and abundance differed over the years from 2009-2016, but, similar to the seed bank, these metrics were relatively higher in 2012 and 2014 (Fig. 1b and 1d). The vegetation coverage, herb biomass, and litter also showed basically similar trends, with herb biomass and litter showing larger annual fluctuations (Fig. S2).

\subsection{The effects of environmental factors and aboveground vegetation on the seed bank}

The first structural equation model $\left(X^{2}=23.410, \mathrm{DF}=3, \mathrm{CMIN} / \mathrm{DF}=7.807, \mathrm{GFI}=0.958, \mathrm{CFI}=0.919\right.$, RMSEA $=0.215$ ) showed that rainfall in the growing season (April to October) had a both positive direct effect on species richness and abundance of the seed bank and an indirect effect through its impact on the 
aboveground vegetation (Fig. 2a, Table S3). Soil water content and wind velocity had a positive and a negative effect on the seed bank abundance, respectively. The second structural equation model $\left(X^{2}=\right.$ 26.050, $\mathrm{DF}=5, \mathrm{CMIN} / \mathrm{DF}=5.210, \mathrm{GFI}=0.953, \mathrm{CFI}=0.876, \mathrm{RMSEA}=0.169)$ showed that the quadrat elevation had a direct negative effect on the seed bank species richness and abundance and an indirect effect on the seed bank abundance through the aboveground vegetation abundance (Fig. 2b, Table S4). However, no significant paths were found leading from microtopographic factors to shrub cover and then to the seed bank.

\subsection{The relationship between the soil seed bank and aboveground vegetation}

The species composition of the soil seed bank and the aboveground vegetation for all species were divided into two groups in two dimensions of the NMDS (Fig. 3a). The ordination distance within the seed bank was $0.337+-0.002$ (Mean +- SE; CV $=1.53 \%$ ), which was smaller than that within aboveground vegetation $(0.505+-0.051 ; \mathrm{CV}=26.5 \%)$. The within-group ordination distance of both groups was significantly smaller than the distance between them $(1.347+-0.260, p<0.001$; CV $=19.3 \%)$. For shrubs and perennials, the species composition of the soil seed bank and the aboveground vegetation were also divided into two groups (Fig. 3b, c), and the within-group ordination distance for each group was significantly smaller than the distance between them $(p<0.001$; Table 1). For annuals, however, the species composition of the soil seed bank clustered together with the aboveground vegetation (Fig. 3d) and the within-group ordination distance of the two groups did not differ significantly from the ordination distance between them $(p=0.092$; Table 1$)$. In addition, the ordination distances within the soil seed bank did not differ significantly among the three life forms $(p=0.285$; Table1). Overall, these results indicate that the species composition of seed bank samples had less annual change and more similarity than the aboveground vegetation. When considering different life forms, the similarity of species composition between the soil seed bank and aboveground vegetation was lower for shrubs and perennials than for annuals.

\section{Discussion}

As climate change and anthropogenic disturbance affect terrestrial ecosystems, ecologists have made great efforts to explore the role of soil seed banks in maintaining ecological stability and reconstructing degraded ecosystems (Chang et al., 2001; Jacquemyn et al., 2011; Kalamees et al., 2013). Three key points distinguish our study from previous studies on this topic. First, we considered the effects of both environmental factors and the aboveground vegetation on the soil seed bank. Second, our study clearly showed that annuals, which are modified by rainfall in the growing season, had a direct effect on seed bank size. Third and most important, we demonstrated that the species composition fluctuated less in the seed bank than in the aboveground plant communities.

\subsection{Effect of rainfall, quadrat elevation and shrub coverage on the soil seed bank}

Our first hypothesis, that rainfall in the growing season is the most critical environmental factor influencing soil seed bank, was verified. The SEM results showed that rainfall exerts both direct and indirect effects on the species composition and size of the soil seed bank. In arid regions, an increase in rainfall could promote the growth of plants, especially herbs, leading to greater seed production and a larger seed bank (Shen \& Ehrenfeld, 2009). On the other hand, biological soil crusts, which exist widely in deserts and maintain soil structure and moisture, could prevent these seeds from entering the soil (X. R. Li et al., 2005). Intense rainfall events, however, can break the structure of biological soil crusts and allow seeds passage into the soil (Pando-Moreno, Molina-Guerra, Jurado, \& Flores, 2014; Rivera-Aguilar, Godinez-Alvarez, ManuellCacheux, \& Rodriguez-Zaragoza, 2005). In addition, a possible explanation for the negative effect of wind velocity on seed bank abundance is that higher wind velocity may promote the dispersal of seeds over long distances, thereby reducing the seeds in this site and making conditions unsuitable for seeds entering the soil.

The quadrat elevation was negatively related to the soil seed bank (Fig. 2), in agreement with previous findings (Gomaa, 2014, 2018; Liu, Xiong, Jiang, Liu, \& Liu, 2016). Higher elevation sites do not capture or retain seeds well because wind and gravity drive seeds downhill (C. Li, Xiao, Wang, Zheng, \& Wu, 2017). 
Hydrothermal differences caused by microtopography may also determine whether seeds can germinate or lie dormant in the soil (Novak, Wawrosch, Schmiderer, Franz, \& Kopp, 2011; Thompson, Ceriani, Bakker, \& Bekker, 2003). In addition, quadrats at relatively higher elevation are limited by lower soil moisture and nutrients and tend to have relatively poor vegetation growth, which thus leads to lower seed yields compared with lower locations (Havrdova, Douda, \& Doudova, 2015).

Generally speaking, shrubs could accumulate larger seed banks by trapping seeds. In our results, however, no significant relationships were found between shrub coverage and the species richness and abundance of the seed bank. This discrepancy may be explained by the slight differences in shrub coverage over the study site, which translated into a slight difference in capturing seeds due to the changed microenvironment (Tackenberg \& Stocklin, 2008). This probably also occurred because the shrubs may restrict the growth of annuals and thus reduce seed yields (Aguiar \& Sala, 1997; Ozinga et al., 2004). However, these results highlight the complexity of how both aboveground vegetation and microenvironment influence soil seed bank, and emphasize the need to further explore the combined effects of shrub coverage and microenvironment in desert ecosystems.

\subsection{Similarity between seed bank and aboveground vegetation and the effect of annuals on the seed bank}

Consistent with our second hypothesis, we found that the synchronous changes in the soil seed bank and the aboveground vegetation mainly depended on annuals, which suggests a tight within-year coupling between the soil seed bank and aboveground vegetation in desert ecosystems. The relationship between the seed bank and annuals of aboveground vegetation clearly demonstrated that the growth of annuals could have a direct and immediate effect on the soil seed bank.

The seed yields of annuals are often much higher than of other lifeforms, which may rely more on vegetative reproduction (Martiniello, 1999). In our study, for example, the dominant shrubs, Artemisia ordosica and Caragana korshinskii and the perennials Iris tenuifolia and Allium mongolicum, can all reproduce by cloning their branches and/or rhizomes (F. Y. Ma et al., 2002). Further exacerbating this difference, the smaller seed size of annuals means that they can more easily penetrate gaps in the biological soil crusts in our study area (X. R. Li et al., 2005; Pando-Moreno et al., 2014). In addition, seeds of annuals usually have a shorter dormancy time than seeds of shrubs and perennials (Finch-Savage \& Leubner-Metzger, 2006). In our study, we used the seedling emergence method to define the soil seed bank, and the soil samples were watered frequently. Under these sufficient water conditions, annuals often break their dormancy and germinate rapidly (Jakobsson \& Eriksson, 2003; Novak et al., 2011). Overall, our results showed synchronous changes between the seed bank and aboveground vegetation, and future studies should focus on elucidating how the population dynamics of individual species in the seed bank respond to changes in the aboveground vegetation of deserts.

\subsection{Variation in soil seed bank}

We found that annual changes in the composition of the soil seed bank were smaller and had less fluctuation than did changes in aboveground vegetation, which supported our third hypothesis and also mirrored similar results from other ecosystems, such as in arctic coastal marsh, alpine meadows, and other arid ecosystems (Chang et al., 2001; M. J. Ma et al., 2017; Zhang et al., 2016). There are several reasons for these results. First, the low species diversity of the seed bank itself could directly result in its small annual change in species composition. Second, the vegetation of arid environments tends to have more taxa with dormant seeds than benign environments do (J. P. Bakker et al., 1996; Kalamees et al., 2013). Seed dormancy facilitates a sustainable and long-term seed bank in temporally and spatially unpredictable environments, such as deserts. In many cases, breaking dormancy requires a period of cold-stratification before either germinating or re-entering dormancy (Kleemann \& Gill, 2013). Seed dormancy is an adaptive trait, a way to maximize progeny number by extending seed lifetime (Facelli, Chesson, \& Barnes, 2005). Therefore, dormant seeds increase the stability of seed bank composition, and this persistent seed bank could therefore act as an important resource for restoration and management (J. P. Bakker et al., 1996; Kalamees et al., 
2013).

As the constructive and dominant lifeform in deserts, shrubs play a decisive role in the stability of the ecosystem (F. Y. Ma et al., 2002). Perennials are also an important component of ecosystem resilience and resistance (Abella \& Smith, 2013). However, in our study the species compositions and individual proportions of shrubs and perennials in the seed bank were greatly lower than those of the aboveground plant communities. Although the species composition of the soil seed bank had less fluctuation than the aboveground plant communities in our study, the lack of shrub and perennial seeds may inhibit the regeneration of such species when considering the recovery and restoration of degraded desert ecosystems.

\section{Conclusion}

Based on a long-term continuous observational study, we evaluated the effects of environmental factors and aboveground vegetation on the species composition and size of a desert soil seed bank. Rainfall in the growing season had a substantial positive effect on the soil seed bank richness and abundance, while quadrat elevation had a negative effect on the seed bank. The synchronous changes in the soil seed bank and aboveground vegetation were mainly driven by annuals. The species composition of the seed bank had more similarity and less fluctuation than the aboveground vegetation, indicating that the seed bank may have great potential to be a source of restoration for degraded desert ecosystems. However, because of the low diversity and abundance of shrub and perennial seeds and the fast response of annual seeds to rainfall, it may be difficult to restore a degraded desert by relying solely on the seed bank and natural regeneration. Our study highlights the importance of long-term investigations of the soil seed bank and the requirement of appropriate interventions, such as artificial reseeding of shrubs and perennials, to promote the restoration of arid degraded ecosystems.

\section{Acknowledgements}

This work was supported by the National Natural Science Foundation of China (Grant No. 3197529) and the Strategic Priority Research Program of the Chinese Academy of Sciences (XDA23060200). We would like to thank Prof. Simon Queenborough and Elizabeth Tokarz at the Yale University for their assistance with English language editing of the manuscript.

\section{Declaration of conflict of interests}

The authors declare that they have no known competing financial interests or personal relationships that could have appeared to influence the work reported in this paper.

\section{Data availability statement}

The data that support the findings of this study are available from the corresponding author upon reasonable request.

\section{Reference}

Abella, S. R., \& Smith, S. D. (2013). Annual-perennial plant relationships and species selection for desert restoration. Journal of Arid Land, 5 , 298-309. doi:10.1007/s40333-013-0172-0

Aguiar, M. R., \& Sala, O. E. (1997). Seed distribution constrains the dynamics of the Patagonian steppe. Ecology, 78 , 93-100. doi:10.2307/2265981

Arruda, A. J., Buisson, E., Poschlod, P., \& Silveira, F. A. O. (2018). How have we studied seed rain in grasslands and what do we need to improve for better restoration? Restoration Ecology, 26 , S84-S91. doi:10.1111/rec.12686

Bai, Y. X., She, W. W., Zhang, Y. Q., Qiao, Y. G., Fu, J., \& Qin, S. G. (2020). N enrichment, increased precipitation, and the effect of shrubs collectively shape the plant community in a desert ecosystem in northern China. Science of the Total Environment, 716 , 135379. doi:10.1016/j.scitotenv.2019.135379 
Bakker, J. P., \& Berendse, F. (1999). Constraints in the restoration of ecological diversity in grassland and heathland communities. Trends in Ecology and Evolution, 14 , 63-68. doi:10.1016/S0169-5347(98)01544-4

Bakker, J. P., Poschlod, P., Strykstra, R. J., Bekker, R. M., \& Thompson, K. (1996). Seed banks and seed dispersal: important topics in restoration ecology. Plant Biology, 45 , 461-490. doi:10.1111/j.14388677.1996.tb00806.x

Boudell, J. A., Link, S. O., \& Johansen, J. R. (2002). Effect of soil microtopography on seed bank distribution in the shrub-steppe. Western North American Naturalist, 62 , 14-24.

Brandel, M., \& Schutz, W. (2005). Temperature effects on dormancy levels and germination in temperate forest sedges (Carex). Plant Ecology, 176 , 245-261. doi:10.1007/s11258-004-0117-y

Chang, E. R., Jefferies, R. L., \& Carleton, T. J. (2001). Relationship between vegetation and soil seed banks in an arctic coastal marsh. Journal of Ecology, 89 , 367-384. doi:10.1046/j.1365-2745.2001.00549.x

Chen, Y. L., Zhang, Z. S., Zhao, Y., Hu, Y. G., \& Zhang, D. H. (2018). Soil carbon storage along a 46-year revegetation chronosequence in a desert area of northern China. Geoderma, 325 , 28-36. doi:10.1016/j.geoderma.2018.03.024

Clarke, K. R. (1993). Non-parametric multivariate analyses of changes in community structure. Austral Ecology, 18 , 117-143. doi:10.1111/j.1442-9993.1993.tb00438.x

Facelli, J., Chesson, P., \& Barnes, N. (2005). Differences in seed biology of annual plants in arid lands: A key ingredient of the storage effect. Ecology, 86 , 2998-3006. doi:10.1890/05-0304

Fenner, M., \& Thompson, K. (2005). The Ecology of Seeds . Cambridge: Cambridge University Press.

Finch-Savage, W. E., \& Leubner-Metzger, G. (2006). Seed dormancy and control of germination. New Phytologist, 171 , 501-523. doi:10.1111/j.1469-8137.2006.01787.x

Gomaa, N. H. (2014). Microhabitat variations and seed bank-vegetation relationships in a desert wadi ecosystem. Flora, 209 , 725-732. doi:10.1016/j.flora.2014.09.004

Gomaa, N. H. (2018). Reproductive traits, flowering phenology and seed bank dynamics in Retama raetam (Fabaceae) in a hyper-arid environment. Arid Land Research and Management, 33 , 1-21. doi:10.1080/15324982.2018.1510440

Havrdova, A., Douda, J., \& Doudova, J. (2015). Local topography affects seed bank successional patterns in alluvial meadows. Flora, 217, 155-163. doi:10.1016/j.flora.2015.10.007

Hu, A., Zhang, J., Chen, X., Chang, S., \& Hou, F. (2019). Winter grazing and rainfall synergistically affect soil seed bank in semiarid area. Rangeland Ecology and Management, 72 , 160-167. doi:10.1016/j.rama.2018.07.012

Huang, Z., Footitt, S., Tang, A., \& Finch-Savage, W. E. (2018). Predicted global warming scenarios impact on the mother plant to alter seed dormancy and germination behaviour in Arabidopsis. Plant Cell and Environment, 41 , 187-197. doi:10.1111/pce.13082

Jacquemyn, H., Van Mechelen, C., Brys, R., \& Honnay, O. (2011). Management effects on the vegetation and soil seed bank of calcareous grasslands: an 11-year experiment. Biological Conservation, 144 , 416-422. doi:10.1016/j.biocon.2010.09.020

Jaganathan, G. K., Dalrymple, S. E., \& Liu, B. L. (2015). Towards an understanding of factors controlling seed bank composition and longevity in the alpine environment. Botanical Review, 81 , 70-103. doi:10.1007/s12229-014-9150-2

Jakobsson, A., \& Eriksson, O. (2003). A comparative study of seed number, seed size, seedling size and recruitment in grassland plants.Oikos, 88 , 494-502. doi:10.1034/j.1600-0706.2000.880304.x 
Kalamees, R., Pussa, K., Zobel, K., \& Zobel, M. (2013). Restoration potential of the persistent soil seed bank in successional calcareous (alvar) grasslands in Estonia. Applied Vegetation Science, 15 , 208-218. doi:10.1111/j.1654-109X.2011.01169.x

Kindt, R., \& Coe, R. (2005). Tree diversity analysis. A manual and software for common statistical methods for ecological and biodiversity studies . Nairobi, Kenya: World Agroforestry Centre (ICRAF).

Kleemann, S., \& Gill, G. (2013). Seed dormancy and seedling emergence in ripgut brome (Bromus diandrus ) populations in southern Australia. Weed Science, 61 , 222-229. doi:10.1614/WS-D-12-00083.1

Li, C., Xiao, B., Wang, Q., Zheng, R., \& Wu, J. (2017). Responses of soil seed bank and vegetation to the increasing intensity of human disturbance in a semi-arid region of northern China.Sustainability, 9 , 1837. doi:10.3390/su9101837

Li, X. R., Jia, X. H., Long, L. Q., \& Zerbe, S. (2005). Effects of biological soil crusts on seed bank, germination and establishment of two annual plant species in the Tengger Desert (N China). Plant and Soil, 277 , 375-385. doi:10.1007/s11104-005-8162-4

Liu, H., Xiong, Z. Q., Jiang, X. L., Liu, G. H., \& Liu, W. Z. (2016). Heavy metal concentrations in riparian soils along the Han River, China: The importance of soil properties, topography and upland land use.Ecological Engineering, 97 , 545-552. doi:10.1016/j.ecoleng.2016.10.060

Ma, F. Y., Li, X. R., Long, L. Q., \& Zhang, J. G. (2002). Population structure and regeneration of planted Artemisia ordocisa in Shapotou. Journal of Desert Research, 22 , 571-575. doi:10.1088/1009-1963/11/5/313 (In Chinese)

Ma, M. J., Baskin, C. C., Li, W. J., Zhao, Y. P., Zhao, Y., Zhao, L., . . . Du, G. Z. (2019). Seed banks trigger ecological resilience in subalpine meadows abandoned after arable farming on the Tibetan Plateau.Ecological Applications, 29 , e01959. doi:10.1002/eap.1959

Ma, M. J., Dalling, J. W., Ma, Z., \& Zhou, X. H. (2017). Soil environmental factors drive seed density across vegetation types on the Tibetan Plateau. Plant and Soil, 419 , 349-361. doi:10.1007/s11104-017-3348-0

Martiniello. (1999). Effects of irrigation and harvest management on dry-matter yield and seed yield of annual clovers grown in pure stand and in mixtures with graminaceous species in a Mediterranean environment. Grass and Forage Science, 54, 52-61. doi:10.1046/j.1365-2494.1999.00153.x

Montiel, S., \& Montana, C. (2003). Seed bank dynamics of the desert cactus Opuntia rastrera in two habitats from the Chihuahuan Desert. Plant Ecology, 166 , 241-248. doi:10.1023/A:1023255314277

Nano, C. E. M., Bowland, A. E., \& Pavey, C. R. (2013). Factors controlling regeneration in a rare desert tree Acacia peuce : Limits to soil seed bank accumulation in time and space. Journal of Arid Environments, 90 , 114-122. doi:10.1016/j.jaridenv.2012.10.012

Novak, J., Wawrosch, C., Schmiderer, C., Franz, C., \& Kopp, B. (2011). Germination responses of Peucedanum ostruthium (Apiaceae) to genotype, light, temperature and gibberellic acid. Seed Science and Technology, 39 , 552-558. doi:10.15258/sst.2011.39.3.02

Oksanen, J., Blanchet, F. G., Friendly, M., Kindt, R., Legendre, P., McGlinn, D., . . . Helene Wagner. (2019). vegan: Community Ecology Package. $R$ package version 2.5-6.https://CRAN.Rproject.org $/$ package $=$ vegan .

Ozinga, W. A., Bekker, R. M., Schaminee, J. H. J., \& Van Groenendael, J. M. (2004). Dispersal potential in plant communities depends on environmental conditions. Journal of Ecology, 92 , 767-777. doi:10.1111/j.0022-0477.2004.00916.x

Pando-Moreno, M., Molina-Guerra, V., Jurado, E., \& Flores, J. (2014). Effect of biological soil crusts on the seed germination of three plant species under laboratory conditions. Botanical Sciences, 92 , 273-279. doi:10.17129/botsci. 57 
Qian, J. Q., Liu, Z. M., Hatier, J. H. B., \& Liu, B. (2016). The Vertical Distribution of Soil Seed Bank and Its Restoration Implication in an Active Sand Dune of Northeastern Inner Mongolia, China. Land Degradation $\&$ Development, 27 , 305-315. doi:10.1002/ldr.2428

Reynolds, J. F., Smith, D. M., Lambin, E. F., Turner, B. L., 2nd, Mortimore, M., Batterbury, S. P., . . . Walker, B. (2007). Global desertification: Building a science for dryland development.Science, 316 , 847-851. doi:10.1126/science.1131634

Rivera-Aguilar, V., Godinez-Alvarez, H., Manuell-Cacheux, I., \& Rodriguez-Zaragoza, S. (2005). Physical effects of biological soil crusts on seed germination of two desert plants under laboratory conditions. Journal of Arid Environments, 63 , 344-352. doi:10.1016/j.jaridenv.2005.03.012

Royo, A. A., \& Ristau, T. E. (2013). Stochastic and deterministic processes regulate spatio-temporal variation in seed bank diversity.Journal of Vegetation Science, 24, 724-734. doi:10.1111/jvs.12011

Shen, Y., \& Ehrenfeld, J. G. (2009). The effects of changes in soil moisture on nitrogen cycling in acid wetland types of the New Jersey Pinelands (USA). Soil Biology and Biochemistry, 41 , 2394-2405. doi:10.1016/j.soilbio.2009.06.012

Snyman, H. A. (2013). Disturbances impact on longevity of grass seeds, semi-arid south African rangeland. Rangeland Ecology and Management, 66 , 143-156. doi:10.2111/REM-D-11-00145.1

Sommer, S., Zucca, C., Grainger, A., Cherlet, M., Zougmore, R., Sokona, Y., . . . Wang, G. (2011). Application of indicator system for monitoring and assessment of desertification from national to global scales. Land Degradation \& Development, 22 , 184-197. doi:10.1002/ldr.1084

Sternberg, M., \& Yu, S. (2004). Soil seed banks, habitat heterogeneity, and regeneration strategies in a Mediterranean coastal sand dune.Israel Journal of Plant Sciences, 52 , 213-221. doi:10.1560/HWL0-7CBQ1DD0-YU0U

Tackenberg, O., \& Stocklin, J. (2008). Wind dispersal of alpine plant species: A comparison with lowland species. Journal of Vegetation Science, 19 , 109-118. doi:10.3170/2007-8-18338

Thompson, K., Ceriani, R., Bakker, J., \& Bekker, R. M. (2003). Are seed dormancy and persistence in soil related? Seed Science Research, 13 , 97-100. doi:10.1079/SSR2003128

Wickham, H. (2016). ggplot2: Elegant Graphics for Data Analysis . Springer-Verlag New York.

Wolters, M., \& Bakker, J. P. (2002). Soil seed bank and driftline composition along a successional gradient on a temperate salt marsh.Applied Vegetation Science, 5 , 55-62. doi:10.1111/j.1654-109X.2002.tb00535.x

Zhang, Z. M., Shen, R., Zhang, J. L., Xu, Q., Luo, Y., Yu, Q. C., . . . Ou, X. K. (2016). Comparisons of species composition between soil seed banks and aboveground plant communities in the dry-hot valley of the Yuanjiang River. Biodiversity Science, 24 , 431-439. doi:10.17520/biods.2015253 (In Chinese)

\section{Figure Legends}

Fig 1. Mean species richness of the soil seed bank (a) and the aboveground plants (b) and abundance of the soil seed bank (c) and the aboveground plants (d) per quadrat in measured years. Values are Mean +SE $(n=37)$.

Fig 2. (a) The first structural equation model (SEM), linking meteorological factors (rainfall, soil water content and wind velocity in the growing season (April to October)) to species richness (VE richness) and abundance (VE abundance) of aboveground vegetation and to species richness (SB richness) and abundance (SB abundance) of the soil seed bank in each quadrat. (b) The second SEM, linking microtopographic conditions (elevation, slope gradient and slope aspect of the quadrat) to species richness and abundance of aboveground vegetation, and shrub coverage to species richness and abundance of the soil seed bank in each quadrat. Purple and green arrows represent positive and negative correlations at 0.05 level, respectively. The thickness of the colored arrows reflects the magnitude of the standardized SEM coefficient. Numbers 
indicate the standard path coefficients. Multiple $\mathrm{R}^{2}$ is displayed at the top of the box for each respective response variable.

Fig 3. Two-dimensional nonmetric multidimensional scaling (NMDS) ordination of soil seed bank (SB1114) and aboveground vegetation (VE09-16) in the measured years. Shown are (a) all species (stress value = 0.083 ); (b) shrubs (stress value $=0.016)$; (c) perennials (stress value $=0.043)$; $(\mathrm{d})$ annuals (stress value $=$ 0.001). Solid green squares and purple triangles represent the soil seed bank and aboveground vegetation, respectively. Colored ellipses represent different species groups based on $85 \%$ level confidence intervals. The location of ordination points within each diagram indicate the degree of similarity between each one in the first two axes of NMDS. Green and purple arrows represent the temporal change of the ordination points of the soil seed bank and aboveground vegetation, and the grey arrow represents the different from the center of the ordination points of the soil seed bank to that of aboveground vegetation; the values next to the arrows represent the ordination distance as calculated from ordination points. The ordination distances within the soil seed bank, within the aboveground vegetation and between the two groups are listed in Table 1 .

Fig 1.
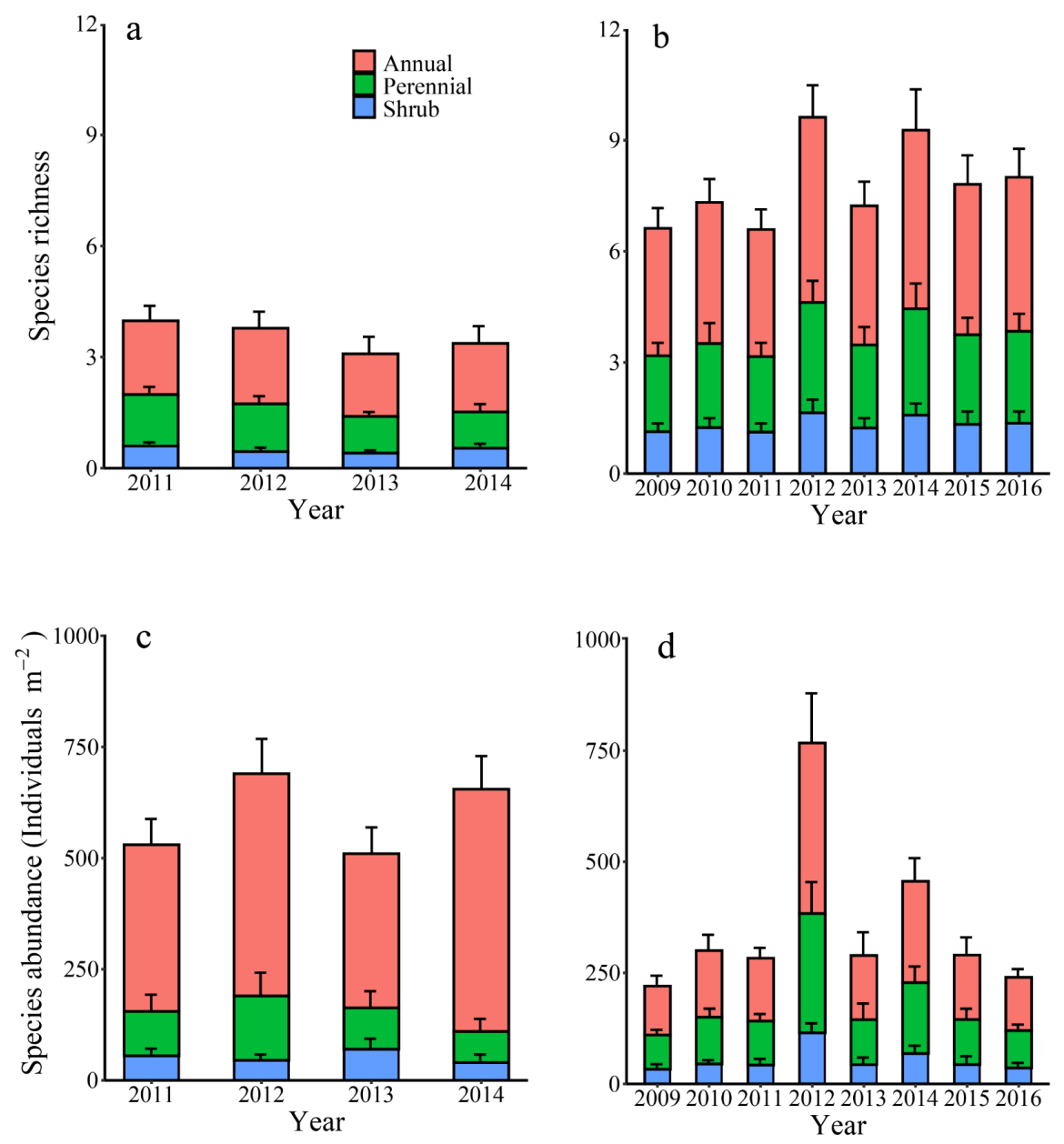

Fig 2. 
a

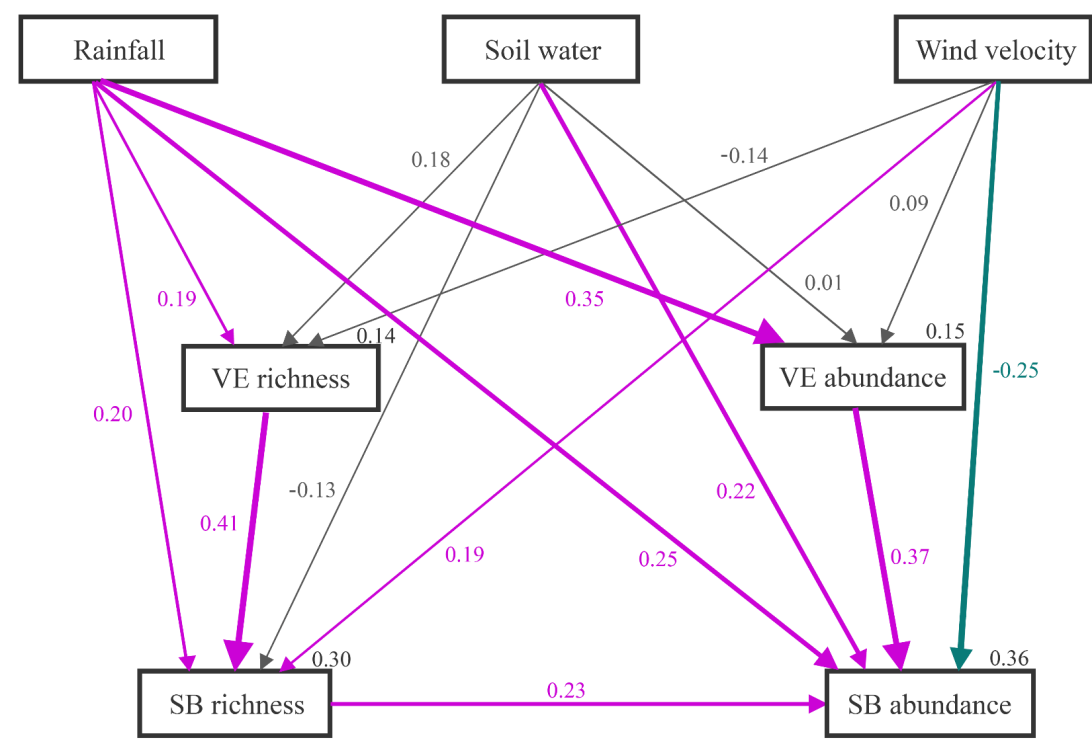

b

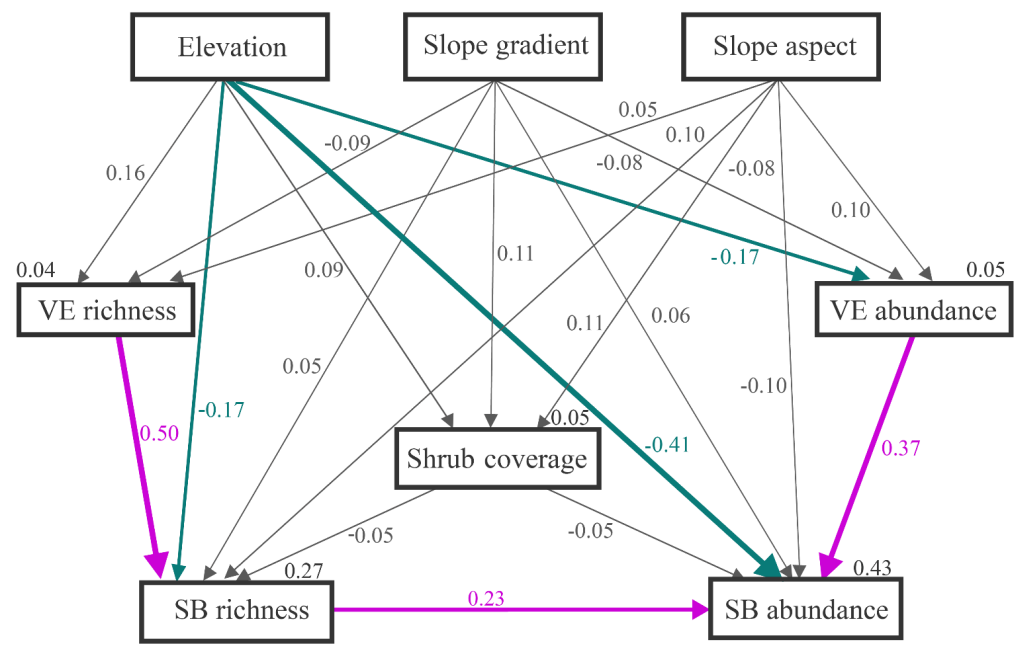

Fig 3. 

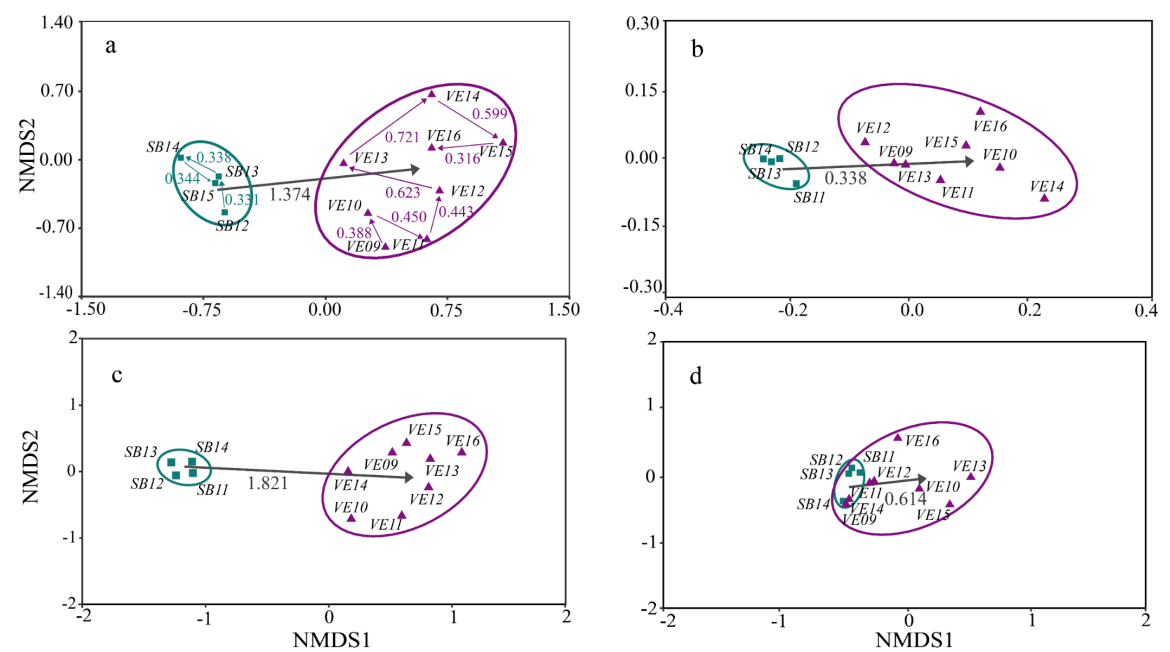

\section{Tables}

Table 1. The ordination distances within the soil seed bank, within the aboveground vegetation and between the two groups for two-dimensional nonmetric multidimensional scaling (NMDS) ordination. Within columns, capital letters represent significant differences in ordination distances among different lifeforms and all species. Within rows, the lowercase letters represent significant differences within the soil seed bank, within the aboveground vegetation and between the two groups for each life form. When the letters are the same, this indicates that the values do not differ significantly from each other, according to post-hoc HSD tests at $p<0.05$ level.

\begin{tabular}{llll}
\hline Lifeforms & $\begin{array}{l}\text { The ordination } \\
\text { distances }(\text { Mean } \pm \mathrm{Se})\end{array}$ & $\begin{array}{l}\text { The ordination } \\
\text { distances }(\text { Mean } \pm \mathrm{Se})\end{array}$ & $\begin{array}{l}\text { The ordination } \\
\text { distances (Mean } \pm \mathrm{Se})\end{array}$ \\
\hline & $\begin{array}{l}\text { within the soil seed bank } \\
(n=3)\end{array}$ & $\begin{array}{l}\text { within the aboveground } \\
\text { vegetation }(n=7)\end{array}$ & $\begin{array}{l}\text { between the two groups } \\
(n=32)\end{array}$ \\
All & $0.337 \pm 0.002 \mathrm{Ab}$ & $0.505 \pm 0.051 \mathrm{ABb}$ & $1.347 \pm 0.046 \mathrm{Ba}$ \\
Shrub & $0.031 \pm 0.026 \mathrm{Bb}$ & $0.199 \pm 0.024 \mathrm{Bb}$ & $0.338 \pm 0.023 \mathrm{Da}$ \\
Perennial & $0.166 \pm 0.006 \mathrm{ABb}$ & $0.603 \pm 0.066 \mathrm{Ab}$ & $1.821 \pm 0.053 \mathrm{Aa}$ \\
Annual & $0.093 \pm 0.071 \mathrm{Ba}$ & $0.826 \pm 0.187 \mathrm{ABa}$ & $0.614 \pm 0.081 \mathrm{Ca}$ \\
\hline
\end{tabular}

